\title{
Effect of a Cholecystokinin Preparation on Brain Monoamines in the Rat
}

\author{
Goro Katsuura, Ryoji Hirota, and Shinji ITOH \\ Shionogi Research Laboratories, Osaka 553, Japan
}

\begin{abstract}
Summary In order to elucidate the central action mechanism of cholecystokinin (CCK), effects of this peptide on norepinephrine, dopamine and serotonin contents in the brain were observed in saline control, $\alpha$-methyl-p-tyrosine-, L-DOPA- and pargyline-pretreated rats. Intraperitoneal injection of CCK in a dose of $40 \mathrm{U} / \mathrm{kg}$ did not produce any significant changes in the monoamine contents. However, since a tendency to increase in norepinephrine turnover rate after CCK injection was noticed, the possibility that brain monoamines are involved in the central action of CCK could not be excluded.
\end{abstract}

Our previous study indicated that intraperitoneal as well as intraventricular injection of a cholecystokinin (CCK) preparation caused a pronounced enhancement of pituitary adrenocortical secretion (Ітон et al., 1979). Effect of C-terminal octapeptide of CCK on the secretion of prolactin, growth hormone, luteinizing hormone and thyrotropin were also reported by VIJAYAN et al. (1979) and MORLEY et al. (1979). The role of hypothalamic monoamines in the secretion of these pituitary hormones has been extensively studied by many investigators. Moreover, CCK is known as a putative satiety hormone which regulates food intake ( $c f$. MUELler and Hsiao, 1978). Regulation of feeding behavior by hypothalamic monoamines was shown by a number of researchers (GROSSMAN, 1962; DAVIS and KEESEY, 1971). Accordingly, it might be assumed that the central effect of CCK is mediated by changes in the brain monoamine metabolism. From this point of view, the present study was carried out to observe the effect of CCK on the brain monoamine contents in rats treated with $\alpha$-methyl-p-tyrosine ( $\alpha$-MT), L-DOPA and pargyline.

Male Wistar rats, weighing approximately $250 \mathrm{~g}$, were used throughout the experiments. They were housed at a constant temperature of $25 \pm 2{ }^{\circ} \mathrm{C}$ under a light: dark ratio of 12:12 hr with lights turned on at 07:00. Rat biscuits (Oriental Yeast Co.) and drinking water were available ad libitum. CCK used in the present experiment was a commercial preparation manufactured by Boots

Received for publication May 17, 1980

勝浦五郎, 広田良二, 伊藤真次 
Co. and its potency was expressed in terms of Harper unit. Other drugs used were $\alpha$-MT (Sigma Co.), L-DOPA (Nakarai Co.) and pargyline (Nakarai Co.). Rats were injected i.p. with $\alpha$-MT in a dose of $200 \mathrm{mg} / \mathrm{kg}$ body weight $12 \mathrm{hr}$ before, injected i.p. with L-DOPA in a dose of $100 \mathrm{mg} / \mathrm{kg} 1 \mathrm{hr}$ before, or given pargyline per os in a dose of $40 \mathrm{mg} / \mathrm{kg} 2 \mathrm{hr}$ before the experiments. These pretreated animals were injected i.p. with CCK in a dose of $40 \mathrm{U} / \mathrm{kg}$ which has been shown to induce a marked increase in the plasma corticosterone level (ITOH et al., 1979) or isotonic saline in the morning at 09:00, and $30 \mathrm{~min}$ later they were sacrificed by decapitation.

The brain was removed as quickly as possible, placed on ice and divided into the telencephalon, diencephalon, hypothalamus and pons +medulla oblongata according to GLOWINSKI and IVERSEN (1966). Hypothalamic tissue obtained from 3 rats was pooled and all samples were kept frozen until analysis. The samples were homogenized in cold $0.4 \mathrm{~N}$ perchloric acid, centrifuged for $10 \mathrm{~min}$ at $1,000 \times g$, and their supernatants were analysed for norepinephrine, dopamine and serotonin contents by the method of KARASAWA et al. (1975). Briefly the supernatant was first passed through double columns consisting of an aluminum oxide column $(0.6 \times 1.0 \mathrm{~cm})$ and an Amberlite CG-50 column $(0.6 \times 1.5 \mathrm{~cm})$. Norepinephrine and dopamine were adsorbed on aluminum oxide in the upper column, while serotonin was retained by Amberlite CG-50 in the bottom column. After washing the columns with distilled water, the amines were eluted with diluted hydrochloric acid. Catecholamines in the eluate were then transformed to fluorescent trihydroxyindole compounds by an oxidation method. As the oxidant, iodine and ferricyanide were used for norepinephrine and for dopamine, respectively. Fluorescence development of serotonin was performed by $o$-phthalaldehyde conjugation. Fluorescent intensities of these samples were measured on a fluorescence spectrometer (Hitachi MPF-2A). For statistical analysis of the data Student's $t$-test was used.

Results are summarized in Table 1. In control rats the norepinephrine content was particularly high in the hypothalamus as compared with the values in other parts of the brain, and the highest content of dopamine was seen in the telencephalon. Serotonin was distributed evenly in the brain, although the content was slightly less in the telencephalon. $\alpha$-MT, which inhibits tyrosine hydroxylase, caused marked decreases in the dopamine and norepinephrine contents, while L-DOPA, precursor of dopamine, produced a large increase in the dopamine content in all regions of the brain. Pretreatment with pargyline, MAO inhibitor, also caused a significant increase of monoamines. However, when the contents of these monoamines after $\mathrm{CCK}$ injection were compared with the respective values of saline controls, no difference was observed, except in one case where the dopamine content in pons + medulla oblongata showed a greater decrease after CCK injection in the $\alpha$-MT pretreated group.

Although changes were not significant, a tendency to decrease in the norepinephrine content after CCK injection may not be overlooked; that is, the 
Table 1. Effect of cholecystokinin (CCK) preparation (40 U/kg, i.p.) on brain monoamine contents in rats treated with $\alpha$-methyl- $p$-tyrosine $(\alpha-\mathrm{MT}), \mathrm{L}$-DOPA and pargyline.

\begin{tabular}{|c|c|c|c|c|c|}
\hline \multirow{2}{*}{ Region group } & \multirow{2}{*}{ Treatment } & \multirow{2}{*}{$\begin{array}{l}\text { No. of } \\
\text { rats }\end{array}$} & Norepinephrine & Dopamine & Serotonin \\
\hline & & & \multicolumn{3}{|c|}{$\mathrm{ng} / \mathrm{g}$ wet weight (mean $\pm \mathrm{SEM}$ ) } \\
\hline \multicolumn{6}{|l|}{ Telencephalon } \\
\hline \multirow[t]{2}{*}{ Control } & Saline & 10 & $347 \pm 11.7$ & $1224 \pm 39.0$ & $414 \pm 24.3$ \\
\hline & $\mathrm{CCK}$ & 10 & $343 \pm 7.2$ & $1256 \pm 50.2$ & $430 \pm 23.7$ \\
\hline \multirow[t]{2}{*}{$\alpha-\mathrm{MT}$} & Saline & 18 & $142 \pm 17.6^{\mathrm{a}}$ & $547 \pm 81.6^{\mathrm{a}}$ & $335 \pm 18.4^{c}$ \\
\hline & $\mathrm{CCK}$ & 18 & $115 \pm 16.9^{\mathrm{a}}$ & $413 \pm 70.6^{\mathrm{a}}$ & $343 \pm 16.1^{b}$ \\
\hline \multirow[t]{2}{*}{ L-DOPA } & Saline & 18 & $327 \pm 10.2$ & $2050 \pm 132.2^{\mathrm{a}}$ & $347 \pm 17.2^{\mathrm{c}}$ \\
\hline & $\mathrm{CCK}$ & 18 & $312 \pm 8.1^{\mathrm{c}}$ & $2036 \pm 120.8^{a}$ & $354 \pm 12.9^{b}$ \\
\hline \multirow[t]{2}{*}{ Pargyline } & Saline & 9 & $474 \pm 19.4^{a}$ & $1658 \pm 57.4^{\mathrm{a}}$ & $516 \pm 18.1^{b}$ \\
\hline & $\mathrm{CCK}$ & 10 & $445 \pm 10.4^{a}$ & $1515 \pm 46.3^{b}$ & $523 \pm 20.9^{b}$ \\
\hline \multicolumn{6}{|l|}{ Diencephalon } \\
\hline \multirow[t]{2}{*}{ Control } & Saline & 15 & $490 \pm 10.8$ & $150 \pm 6.0$ & $667 \pm 49.5$ \\
\hline & $\mathrm{CCK}$ & 15 & $499 \pm 14.7$ & $156 \pm 13.6$ & $677 \pm 58.0$ \\
\hline \multirow[t]{2}{*}{$\alpha-\mathrm{MT}$} & Saline & 18 & $237 \pm 27.9^{a}$ & $75 \pm 10.2^{\mathrm{a}}$ & $454 \pm 39.0^{\mathrm{b}}$ \\
\hline & $\mathrm{CCK}$ & 18 & $188 \pm 22.3^{a}$ & $76 \pm 13.0^{\mathrm{a}}$ & $508 \pm 52.4^{\mathrm{c}}$ \\
\hline \multirow[t]{2}{*}{ L-DOPA } & Saline & 18 & $560 \pm 21.6^{c}$ & $912 \pm 116.2^{\mathrm{a}}$ & $599 \pm 33.4$ \\
\hline & CCK & 18 & $541 \pm 16.5$ & $780 \pm 84.7^{a}$ & $647 \pm 46.7$ \\
\hline \multirow[t]{2}{*}{ Pargyline } & Saline & 18 & $612 \pm 14.4^{\mathrm{a}}$ & $239 \pm 19.3^{\mathrm{a}}$ & $1001 \pm 51.3^{\mathrm{a}}$ \\
\hline & $\mathrm{CCK}$ & 18 & $591 \pm 11.9^{\mathrm{a}}$ & $238 \pm 21.3^{b}$ & $1042 \pm 45.4^{\mathrm{a}}$ \\
\hline \multicolumn{6}{|l|}{ Hypothalamus } \\
\hline \multirow[t]{2}{*}{ Control } & Saline & $18(6)^{*}$ & $1303 \pm 90.7$ & $326 \pm 25.7$ & $605 \pm 88.6$ \\
\hline & $\mathrm{CCK}$ & $18(6)$ & $1202 \pm 54.8$ & $313 \pm 19.3$ & $789 \pm 137.8$ \\
\hline \multirow[t]{2}{*}{$\alpha-\mathrm{MT}$} & Saline & $18(6)$ & $626 \pm 88.1^{\mathrm{a}}$ & $96 \pm 19.3^{a}$ & $411 \pm 94.0$ \\
\hline & CCK & $18(6)$ & $486 \pm 42.6^{a}$ & $88 \pm 17.7^{\mathrm{a}}$ & $447 \pm 127.7$ \\
\hline \multirow[t]{2}{*}{ L-DOPA } & Saline & $18(6)$ & $1124 \pm 69.2$ & $1032 \pm 69.6^{\mathrm{a}}$ & $464 \pm 90.1$ \\
\hline & $\mathrm{CCK}$ & $18(6)$ & $1128 \pm 56.2$ & $1007 \pm 137.3^{\mathrm{a}}$ & $552 \pm 109.9$ \\
\hline \multirow[t]{2}{*}{ Pargyline } & Saline & $18(6)$ & $1455 \pm 71.7$ & $427 \pm 36.1^{\mathrm{c}}$ & $943 \pm 91.7^{c}$ \\
\hline & $\mathrm{CCK}$ & $18(6)$ & $1449 \pm 49.2^{\mathrm{b}}$ & $402 \pm 27.4^{\mathrm{c}}$ & $1011 \pm 56.0^{\mathrm{a}}$ \\
\hline \multicolumn{6}{|c|}{ Pons + Medulla oblongata } \\
\hline \multirow[t]{2}{*}{ Control } & Saline & 10 & $583 \pm 29.6$ & $75 \pm 14.3$ & $663 \pm 29.2$ \\
\hline & $\mathrm{CCK}$ & 10 & $586 \pm 20.5$ & $87 \pm 14.3$ & $701 \pm 54.7$ \\
\hline \multirow[t]{2}{*}{$\alpha-\mathrm{MT}$} & Saline & 18 & $258 \pm 26.5^{\mathrm{a}}$ & $51 \pm 5.7$ & $632 \pm 34.7$ \\
\hline & $\mathrm{CCK}$ & 18 & $195 \pm 22.1^{\mathrm{a}}$ & $32 \pm 4.0^{\mathrm{c}, \mathrm{d}}$ & $607 \pm 44.6$ \\
\hline \multirow[t]{2}{*}{ L-DOPA } & Saline & 18 & $554 \pm 10.6$ & $835 \pm 108.3^{\mathrm{a}}$ & $598 \pm 30.2$ \\
\hline & CCK & 18 & $568 \pm 12.3$ & $769 \pm 97.8^{a}$ & $614 \pm 25.7$ \\
\hline \multirow[t]{2}{*}{ Pargyline } & Saline & 9 & $734 \pm 20.2^{\mathrm{a}}$ & $97 \pm 14.5$ & $860 \pm 33.5^{a}$ \\
\hline & $\mathrm{CCK}$ & 10 & $701 \pm 44.3^{\mathrm{c}}$ & $109 \pm 13.4$ & $890 \pm 31.4^{b}$ \\
\hline
\end{tabular}

${ }^{\mathrm{a}}, P<0.001 ;{ }^{\mathrm{b}}, P<0.01 ;{ }^{\mathrm{c}}, P<0.05$ vs. respective values of control group in the same region; ${ }^{\mathrm{d}}, P<0.01$ vs. saline level in the same subgroup. * Six pooled samples obtained from 18 rats. 
average decreases were $19 \%$ in telencephalon, $21 \%$ in diencephalon, $22 \%$ in hypothalamus and $24 \%$ in pons + medulla oblongata. The results are suggestive of the participation of norepinephrine in the central action of CCK, but direct evidence for an increased turnover rate of norepinephrine is required. The action mode of CCK other than controlling the monoamine metabolism should be investigated in further studies. The important role of monoamines in various central nervous functions are known, and the central action of CCK has attracted considerable attention by many investigators because of its abundance in the brain (DoCKRAY, 1976; ReHFeld, 1978; ReHFELd et al., 1979). The present observations make up one step of a series of experiments on the central action of CCK.

\section{REFERENCES}

DAvis, J. R. and KeESEY, R. E. (1971) Norepinephrine-induced eating: Its hypothalamic locus and an alternate interpretation of action. J. Comp. Physiol. Psychol., 77: 394-402.

Dockray, G. J. (1976) Immunochemical evidence of cholecystokinin-like peptides in brain. Nature, 264: 568-570.

Glowinski, J. and IVERSEN, L. L. (1966) Regional studies of catecholamines in the rat brain. J. Neurochem., 13: 655-669.

Grossman, S. P. (1962) Direct adrenergic and cholinergic stimulation of hypothalamic mechanisms. Am. J. Physiol., 202: 872-882.

Itoh, S., Hirota, R., Katsuura, G., and Odaguchi, K. (1979) Adrenocortical stimulation by a cholecystokinin preparation in the rat. Life Sci., 25: 1725-1730.

Karasawa, T., Furukawa, K., Yoshida, K., and Shimizu, M. (1975) A double column procedure for the simultaneous estimation of norepinephrine, normetanephrine, dopamine, 3-methoxytyramine and 5-hydroxytryptamine in brain tissue. Jpn. J. Pharmacol., 25: 727-736.

Morley, J. E., Meimed, S., Briggs, J., Carlson, H. E., Hershman, J. M., Solomon, T. E , LAMERS, C., and Damassa, D. A. (1979) Cholecystokinin octapeptide releases growth hormone from the pituitary in vitro. Life Sci., 25: 1201-1206.

Mueller, K. and Hsiao, S. (1978) Current status of cholecystokinin as a short-term satiety hormone. Neurosci. Biobehav. Rev., 2: 79-87.

REHFELD, J. F. (1978) Immunochemical studies on cholecystokinin. II. Distribution and molecular heterogeneity in the central nervous system and small intestine of man and hog. J. Biol. Chem., 253: 4022-4030.

Rehfeld, J. F., Goltermann, N., Larsson, L. I., Emson, P. M., and Lee, C. M. (1979) Gastrin and cholecystokinin in central and peripheral neurons. Fed. Proc., 38: 2325-2329.

ViJAYAN, E., SAMSON, W. K., and MCCANN, S. M. (1979) In vivo and in vitro effects of cholecystokinin on gonadotropin, prolactin, growth hormone and thyrotropin release in the rat. Brain Res., 172: 295-302. 